\title{
Investigation of Biofilm Forming Ability in Staphylococci Causing Bovine Mastitis Using Phenotypic and Genotypic Assays
}

\author{
Samah F. Darwish ${ }^{1}$ and Hanaa A. E. Asfour ${ }^{2}$ \\ ${ }^{1}$ Biotechnology Research Unit, Animal Reproduction Research Institute (ARRI), Giza, Egypt \\ ${ }^{2}$ Department of Mastitis and Neonatal Diseases, Animal Reproduction Research Institute (ARRI), Giza, Egypt
}

Correspondence should be addressed to Samah F. Darwish; samahtarek@hotmail.com

Received 4 August 2013; Accepted 5 September 2013

Academic Editors: M. Fernandez, H. Omoe, and L. Visai

Copyright (c) 2013 S. F. Darwish and H. A. E. Asfour. This is an open access article distributed under the Creative Commons Attribution License, which permits unrestricted use, distribution, and reproduction in any medium, provided the original work is properly cited.

\begin{abstract}
A total of 40 S. aureus and 68 coagulase negative Staphylococcus (CNS) isolates from bovine subclinical mastitis were investigated for their ability to form biofilm as one of the most important virulence factors. Using Congo Red Agar (CRA) method, 32.5\%, $35 \%$, and $32.5 \%$ of $S$. aureus strains were strong, intermediate, and negative biofilm producers, while in CNS the percentages were $29.5 \%, 42.6 \%$, and 27.9\%, respectively. By microtiter plate (MTP) method, $52.5 \%, 27.5 \%$, and 20\% of S. aureus isolates were strong, moderate, and weak biofilm producers, while in CNS the percentages were $44 \%, 30.9 \%$, and $19.2 \%$, respectively. Indian ink staining was used to detect the EPS layer of biofilm producers. All isolates were screened for presence of biofilm related genes, eno, icaA, $i c a D$, and bap. In S. aureus isolates, the positive rates of eno, icaA, icaD, and bap genes were $75 \%, 15 \%, 62.5 \%$, and $2.5 \%$ while in CNS were $92.6 \%, 5.9 \%, 47.1 \%$, and $4.4 \%$, respectively. The eno gene had the highest rate while the bap gene had the lowest rate. Presence of icaA and icaD genes was not always correlated with biofilm production. This study demonstrated high prevalence of Staphylococcus biofilm producers among bovine mastitis in Egypt. Therefore, attention must be paid toward implementation of new ways for effective treatment of such infections.
\end{abstract}

\section{Introduction}

Bovine mastitis caused by $S$. aureus and coagulase negative Staphylococci (CNS) remains a substantial problem for milk producers worldwide. The pathogenesis of Staphylococcus mastitis is attributed to a combination of extracellular factors and properties such as adherence and biofilm formation $[1,2]$.

Biofilm is an exopolysaccharide, a slime matrix around multiple layers of cells. The ability of Staphylococci to form biofilms is one of the virulence factors that facilitate the adherence and colonization of Staphylococci on the mammary gland epithelium, also contributing to the evasion of the immunological defences and to the difficulty of pathogen eradication, leading to recurrent or persistent infections [3-8].

Staphylococcus biofilm formation mechanisms are complex and include the participation of many kinds of proteins, and so many genes are involved. It is considered to be a two-step process. Firstly, the bacteria adhere to a surface mediated by a capsular antigen, namely, capsular polysaccharide/adhesin (PS/A). Then, the bacteria multiply to form a multilayered biofilm, which was associated with production of polysaccharide intercellular adhesin (PIA). The intercellular adhesion (ica) locus consisting of the genes $i c a A D B$ and $C$ encodes the proteins mediating the synthesis of PIA and PS/A in staphylococcal species $[1,9]$.

Monitoring the biofilm forming ability of Staphylococci causing mastitis and the genes involved in it may provide new ideas or strategy for the prevention or the effective treatment of bovine mastitis. According to our knowledge, in Egypt, researches on biofilm only began recently and mainly focused on Staphylococcus clinical isolates from human sources [10, 11]. So, the aim of the present study was to investigate the biofilm forming ability of Staphylococcus strains causing bovine mastitis using different phenotypic methods. Moreover, the detection of some biofilm related genes in these strains and their involvement with biofilm will be evaluated. 


\section{Material and Methods}

2.1. Bacterial Isolates. The investigation was carried out on 108 Staphylococcus isolates recovered from bovine subclinical mastitic milk. The isolates were identified by their cultural characteristics on blood agar, mannitol salt agar, and Baird Parker agar media, microscopic appearance in Gram stained preparations, positive catalase reaction, hemolysin, and coagulase test (tube method) with rabbit plasma and biochemical analysis according to Quinn et al. [12].

\subsection{Biofilm Formation Assays}

\subsubsection{Phenotypic Analysis}

(1) Detection of Slime Production by Congo Red Agar Method. Slime production was evaluated by cultivation of all Staphylococcus isolates on Congo Red Agar (CRA) plates as described by Mathur et al. [13] (2006). Briefly, CRA plates were prepared using Tryptic Soy agar containing 0.08\% Congo red (Sigma). The inoculated CRA plates were incubated at $37^{\circ} \mathrm{C}$ in aerobic conditions for $24 \mathrm{~h}$, followed by storage at room temperature for $48 \mathrm{~h} \mathrm{[4].} \mathrm{Isolates} \mathrm{were} \mathrm{interpreted} \mathrm{according} \mathrm{to} \mathrm{their}$ colony phenotypes [14]. Black colonies with dry consistency and rough surface and edges were considered a positive indication of slime production, while both black colonies with smooth, round, and shiny surface and red colonies of dry consistency and rough edges and surface were considered as intermediate slime producers. Red colonies with smooth, round, and shiny surface were indicative of negative slime production.

(2) Detection of Biofilm by Microtiter Plate (MTP) Method. All Staphylococcus isolates were grown overnight at $37^{\circ} \mathrm{C}$ as pure cultures on blood agar. Groups of three single colonies were inoculated in $3 \mathrm{~mL}$ Tryptone Soya broth. Suspensions were incubated for $24 \mathrm{~h}$ at $37^{\circ} \mathrm{C}$ and then diluted at $1: 40$ in a fresh TSB $\left(2-7 \times 10^{7} \mathrm{cfu} / \mathrm{mL}\right)$ using 0.5 MacFarland standard tube. This dilution was used as the inoculum in the microtiter plate test. Microtiter plate test was performed according to Dubravka et al. [14] and Stepanović et al. [15]. For each Staphylococcus isolate, $200 \mu \mathrm{L}$ aliquots of prepared suspension were inoculated into four wells of the 96-well tissue culture plates (Nunclon Delta, Nunc, Roskilde, Denmark). Each culture plate included a negative control, four wells with TSB. The plates were incubated at $37^{\circ} \mathrm{C}$ for $24 \mathrm{~h}$. Afterwards, content of each well was removed by aspiration and the wells were rinsed three times with $250 \mu \mathrm{L}$ sterile physiological saline. The plates were dried in inverted position. The attached bacteria were fixed for 15 minutes at room temperature by adding $200 \mu \mathrm{L}$ volumes of methanol into each well. The plates were stained with $160 \mu \mathrm{L}$ aqueous solution of crystal violet $0.5 \%$ (Crystal Violet, Fluka) for 15 minutes at room temperature. Following staining, the plates were rinsed under running water until there was no visible trace of stain. The stain bound to bacteria was dissolved by adding $160 \mu \mathrm{L}$ of $95 \%$ ethanol. The optical density (OD) of each well was measured using a microplate ELISA reader ( $E_{\max }, \mathrm{USA}$ ) at $570 \mathrm{~nm}$. Cut-off OD (ODc) is defined as three standard deviations above the mean OD of the negative control. Strains were interpreted as follows:

(1) nonbiofilm producers (OD $\leq \mathrm{ODc})$;

(2) weak biofilm producers (ODc $<\mathrm{OD} \leq 2 \times \mathrm{ODc}$ );

(3) moderate biofilm producers $(2 \times$ ODc $<$ OD $\leq 4 \times$ ODc);

(4) Strong biofilm producers $(4 \times \mathrm{ODc}<\mathrm{OD})$.

(3) Detection of Exopolysaccharide Production (EPS). Possible EPS-producing isolates were identified via their mucoid or ropy appearance. EPS production was assessed by Indian ink (Art. Material S.A., China) staining of wet mount preparation of each strain after overnight growth on CRA and examined under light microscope $[16,17]$. Appearance of a transparent halo zone around the Staphylococcus cells denoted the existence of an organized EPS structure.

2.3. Genotypic Analysis. Four biofilm related genes were analyzed by simplex PCR assays to detect the presence of $i c a A$ (intercellular adhesion gene $A$ ), icaD (intercellular adhesion gene $D$ ), bap (encoding biofilm associated protein), and eno (encoding laminin binding protein) in all Staphylococcus isolates. First, crude DNA of the tested strains was extracted using a rapid boiling procedure according to Reischl et al. [18]. Two to 5 loops of Staphylococcus isolates taken from the brain heart infusion agar plate were collected and suspended in $200 \mu \mathrm{L}$ of lysis buffer comprised of $1 \%$ Triton X-100, $0.5 \%$ Tween 20, 10 mM Tris- $\mathrm{HCl}$ ( $\mathrm{pH} 8.0$ ), and $1 \mathrm{mM}$ EDTA. After boiling for $10 \mathrm{~min}$, the suspension was centrifuged for $2 \mathrm{~min}$. to sediment bacterial debris. The supernatant was aspirated, from which $5 \mu \mathrm{L}$ was used directly for PCR amplification. Because of nonavailability of positive controls for the four genes and to exclude any false negative results, the DNA of all isolates was firstly examined by amplification of $16 \mathrm{~S}$ rRNA gene using Staphylococcus genus specific primers. The names of target genes, nucleotide sequences of primers, references, annealing temperature, and amplicon sizes are shown in Table 1. The amplification cycles were carried out in a PT100 Thermocycler (MJ Research, USA). With the exception of specific annealing temperatures mentioned in Table 1, the reaction condition was optimized to be $94^{\circ} \mathrm{C}$ for $4 \mathrm{~min}$. as initial denaturation, followed by 40 cycles of $94^{\circ} \mathrm{C}$ for 60 seconds, annealing for 60 seconds and $72^{\circ} \mathrm{C}$ for 60 seconds. A final extension step at $72^{\circ} \mathrm{C}$ for $10 \mathrm{~min}$. was followed. PCR condition was optimized using a total volume of $25 \mu \mathrm{L}$ reaction mixtures which contained $5 \mu \mathrm{L}$ of DNA as template, 25 pmol of each primer, and 1X of PCR master mix (Dream Taq Green PCR Master Mix, Fermentas Life Science). PCR products were analyzed by electrophoresis in $1.5 \%$ agarose gel in $0.5 \mathrm{X}$ TBE buffer containing ethidium bromide and visualized under a UV transilluminator.

2.4. Statistical Analysis. Data were presented as count and percentage. Sensitivity and specificity of CRA method were calculated according to Ilstrup, [22] using $2 \times 2$ table and MTP method as gold standard. The kappa coefficient test was 
TABle 1: Primers used in the study, their nucleotide sequence, annealing temperatures, amplicon sizes, and their references.

\begin{tabular}{|c|c|c|c|}
\hline Gene targeted & $\begin{array}{l}\text { Primer sequence } 5^{\prime}-3^{\prime} \\
\text { (references) }\end{array}$ & Annealing temperature ${ }^{\circ} \mathrm{C}$ & Amplicon size bp \\
\hline $16 S r R N A$ & $\begin{array}{l}\text { GTA GGT GGC AAG CGTTAT CC } \\
\text { CGC ACA TCA GCG TCA G } \\
\text { Monday and Bohach [19] }\end{array}$ & 55 & 228 \\
\hline$i c a A$ & $\begin{array}{l}\text { CCTAACTAACGAAAGGTAG } \\
\text { AAGATATAGCGATAAGTGC } \\
\text { Vasudevan et al. [4] }\end{array}$ & 49 & 1315 \\
\hline$i c a D$ & $\begin{array}{l}\text { AAACGTAAGAGAGGTGG } \\
\text { GGCAATATGATCAAGATAC } \\
\text { Vasudevan et al. }[4]\end{array}$ & 49 & 381 \\
\hline Eno & $\begin{array}{l}\text { ACGTGCAGCAGCTGACT } \\
\text { CAACAGCATYCTTCAGTACCTTC } \\
\text { Tristan et al. [20] }\end{array}$ & 55 & 302 \\
\hline Bap & $\begin{array}{l}\text { CCCTATATCGAAGGTGTAGAATTG } \\
\text { GCTGTTGAAGTTAATACTGTACCTGC } \\
\text { Cucarella et al. [21] }\end{array}$ & 60 & 971 \\
\hline
\end{tabular}

TABLE 2: Biofilm formation in S. aureus and CNS isolates according to CRA method.

\begin{tabular}{lccccc}
\hline \multirow{2}{*}{ Species (no.) } & Positive result & \multicolumn{2}{c}{ No. (\%) of isolates } & \multicolumn{2}{c}{ Negative result } \\
& Dry black & Smooth black & Dry red & Smooth red & Total positive \\
\hline S. aureus (40) & $13(32.5)$ & $8(20)$ & $6(15)$ & $13(32.5)$ & $27(67.5)$ \\
CNS (68) & $20(29.5)$ & $19(27.9)$ & $10(14.7)$ & $19(27.9)$ & $49(72.1)$ \\
\hline Total (108) & $33(30.6)$ & $27(25)$ & $16(14.8)$ & $32(29.6)$ & $76(70.4)$ \\
\hline
\end{tabular}

TABLE 3: Biofilm formation in S. aureus and CNS isolates according to MTP method.

\begin{tabular}{lccccc}
\hline \multirow{2}{*}{ Species (no.) } & \multicolumn{5}{c}{ No. (\%) of isolates } \\
& Strong & Moderate & Weak & Non & $\begin{array}{c}\text { Total } \\
\text { positive }\end{array}$ \\
\hline S. aureus (40) & $21(52.5)$ & $11(27.5)$ & $8(20)$ & $0(0)$ & $40(100)$ \\
CNS (68) & $30(44)$ & $21(30.9)$ & $13(19.2)$ & $4(5.9)$ & $64(94.1)$ \\
\hline Total (108) & $51(47.2)$ & $32(29.7)$ & $21(19.4)$ & $4(3.7)$ & $104(96.3)$ \\
\hline
\end{tabular}

also used to determine the agreement between the results obtained by the CRA method.

\section{Results}

3.1. Bacterial Isolation and Identification. The 108 Staphylococcus isolates were identified to be $40 \mathrm{~S}$. aureus and $68 \mathrm{CNS}$.

\subsection{Biofilm Formation}

3.2.1. Slime Production on Congo Red Agar (CRA). The results of biofilm production by $S$. aureus and CNS using CRA method are demonstrated in Table 2. About $70.4 \%$ of the isolates were positive for biofilm production with varied degree. Out of $40 \mathrm{~S}$. aureus strains, $32.5 \%, 35 \%$, and $32.5 \%$ were strong, intermediate, and negative biofilm producers, respectively. Among the 68 CNS strains, 29.5\%, 42.6\%, and $27.9 \%$ were strong, intermediate, and negative biofilm producers, respectively. Totally, from the 108 Staphylococcus isolates, 33 (30.6\%), 27 (25\%), 16 (14.8\%), and $32(29.6 \%)$ were dry black, smooth black, dry red, and smooth red, respectively. Morphology of all types of colonies is showed in Figure 1.

3.2.2. Biofilm Formation by MTP Method. As shown in Figure 2 and Table 3, approximately $96.3 \%$ of the isolates were biofilm producers with MTP method, although production level varied. The biofilm production of $S$. aureus isolates (100\%) was slightly higher than that of CNS isolates (94.1\%). In the biofilm positive $S$. aureus strains, $52.5 \%$ of isolates were strong producers, while $27.5 \%$ and $20 \%$ were moderate and weak, respectively. Out of the biofilm positive CNS isolates, $44 \%, 30.9 \%$, and $19.2 \%$ were strong, moderate, and weak, respectively.

Comparison of results obtained by CRA method versus that of MTP method is declared in Table 4. Out of 32 biofilm negative Staphylococcus isolates by CRA method, 28 isolates were positive by MTP method but with different degrees of production (4 strong, 8 moderate, 16 weak) and only $4 \mathrm{CNS}$ isolates were true negative by both methods. CRA method showed little correlation with MTP assay where only $76(70.4 \%)$ of the isolates were positive by both methods, kappa coefficient 0.167 slight agreement. The sensitivity and specificity of CRA method versus MTP method as gold standard were calculated to be $73.1 \%$ and $100 \%$, respectively. 


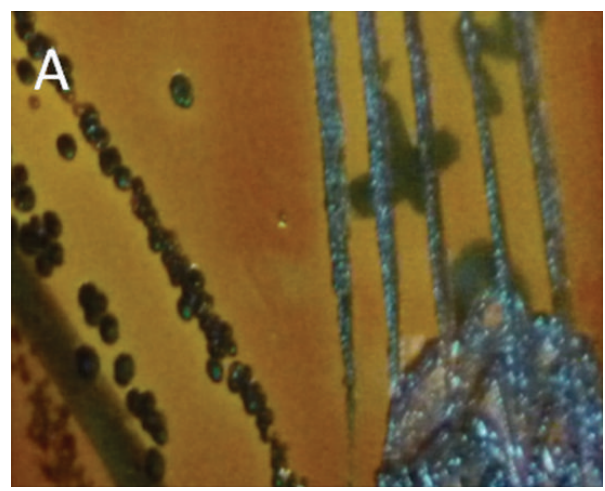

(a)

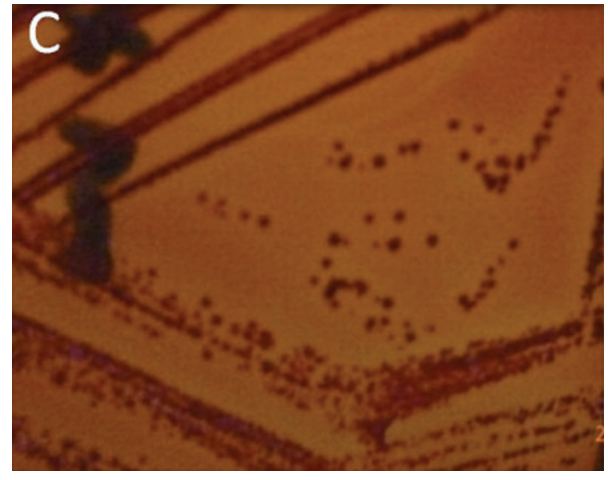

(c)

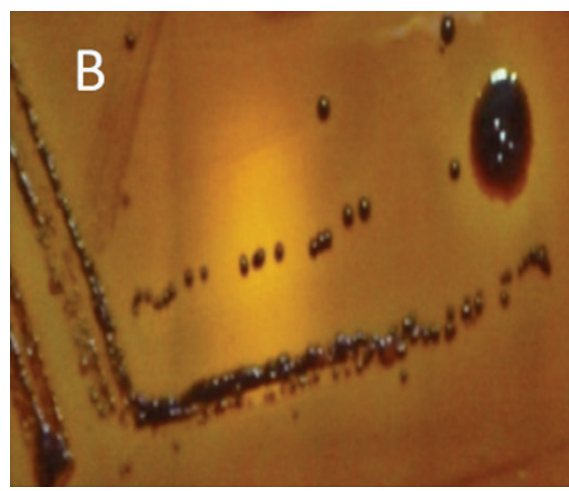

(b)

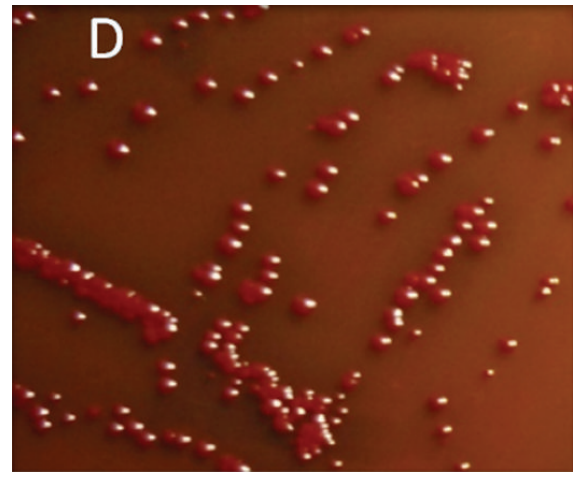

(d)

FIGURE 1: Screening of biofilm (slime) producer Staphylococci using Congo red agar plate method ((a) dry black colonies; (b) smooth black colonies; (c) dry red colonies; (d) smooth red colonies).

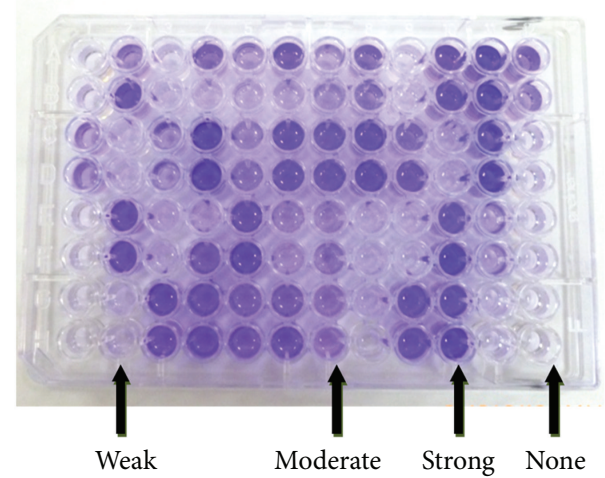

FIGURE 2: 2 Microtiter plate method showing none, strong, moderate, and weak biofilm producers differentiated by crystal violet stain in 96-well tissue culture plate.

3.2.3. Detection of EPS Production. All the 108 Staphylococcus isolates except the 4 biofilm negative CNS showed a distinct halo transparent zone surrounding the grapes linked cells similar to a capsule representing EPS layer (Figure 3).

3.3. Genotypic Analysis of Biofilm Related Genes. All the four biofilm related genes, eno, icaA, icaD, and bap, could be detected in both $S$. aureus and CNS isolates under study
TABLE 4: CRA method versus MTP method for detection of biofilm formation by $S$. aureus and CNS isolates.

\begin{tabular}{lcccccc}
\hline \multirow{2}{*}{ Species } & \multirow{2}{*}{ CRA } & \multirow{2}{*}{ No. } & \multicolumn{4}{c}{ MTP method } \\
& & & Strong & Moderate & Weak & Non \\
\hline \multirow{4}{*}{ S. aureus } & Dryblack & 13 & 12 & 1 & 0 & 0 \\
& Smooth black & 8 & 5 & 2 & 1 & 0 \\
& Dry red & 6 & 1 & 5 & 0 & 0 \\
& Smooth red & 13 & 3 & 3 & 7 & 0 \\
\hline \multirow{4}{*}{ CNS } & Total & 40 & 21 & 11 & 8 & 0 \\
\hline & Dry black & 20 & 17 & 3 & 0 & 0 \\
& Smooth black & 19 & 8 & 9 & 2 & 0 \\
& Dry red & 10 & 4 & 4 & 2 & 0 \\
& Smooth red & 19 & 1 & 5 & 9 & 4 \\
\hline
\end{tabular}

(Figure 4) but with varied prevalence (Figure 5). In S. aureus isolates, the positive rates of eno, icaA, icaD, and bap genes were $75 \%, 15 \%, 62.5 \%$, and $2.5 \%$, respectively (Table 5 and Figure 5). The prevalence of eno, icaA, IcaD, and bap genes in CNS isolates were $92.6 \%, 5.9 \%, 47.1 \%$, and $4.4 \%$, respectively (Figure 5 and Table 5). The prevalence of biofilm related genes varied between $S$. aureus and CNS. The results indicated that the eno gene had the highest rate in CNS (92.6\%) and S. aureus $(75 \%)$ followed by icaD gene which was detected in 
TABLE 5: Association between results of MTP method and positive amplification of biofilm related genes in S. aureus and CNS isolates.

\begin{tabular}{|c|c|c|c|c|c|c|c|c|c|c|}
\hline \multirow{2}{*}{ Species } & \multirow{2}{*}{ MTP } & \multirow{2}{*}{ No. } & \multicolumn{2}{|c|}{ +eno } & \multicolumn{2}{|c|}{$+i c a A$} & \multicolumn{2}{|c|}{$+i c a D$} & \multicolumn{2}{|c|}{$+b a p$} \\
\hline & & & No. & $\%$ & No. & $\%$ & No. & $\%$ & No. & $\%$ \\
\hline \multirow{5}{*}{ S. aureus } & Strong & 21 & 17 & 81 & 5 & 24 & 13 & 62 & 0 & 0 \\
\hline & Moderate & 11 & 9 & 82 & 1 & 9 & 9 & 82 & 0 & 0 \\
\hline & Weak & 8 & 4 & 50 & 0 & 0 & 3 & 37.5 & 1 & 12.5 \\
\hline & None & 0 & 0 & 0 & 0 & 0 & 0 & 0 & 0 & 0 \\
\hline & Total & 40 & 30 & 75 & 6 & 15 & 25 & 62.5 & 1 & 2.5 \\
\hline \multirow{5}{*}{ CNS } & Strong & 30 & 30 & 100 & 3 & 10 & 18 & 60 & 1 & 3.3 \\
\hline & Moderate & 21 & 17 & 81 & 1 & 4.8 & 7 & 33.3 & 0 & 0 \\
\hline & Weak & 13 & 12 & 92.3 & 0 & 0 & 5 & 38.5 & 2 & 15.4 \\
\hline & None & 4 & 4 & 100 & 0 & 0 & 2 & 50 & 0 & 0 \\
\hline & Total & 68 & 63 & 92.6 & 4 & 5.9 & 32 & 47.1 & 3 & 4.4 \\
\hline
\end{tabular}

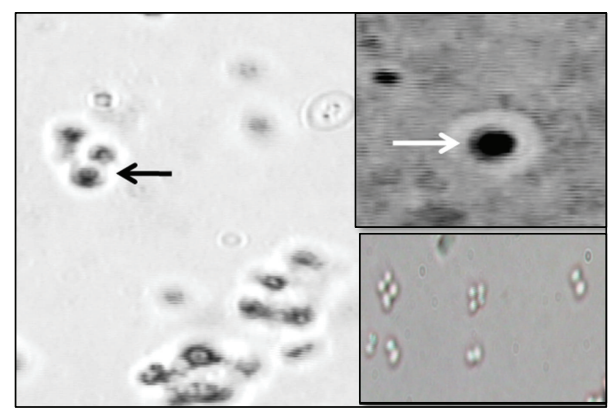

FIGURE 3: Morphology of some of Staphylococcus isolates as observed after staining with Indian ink. The arrows pointed to capsular-like EPS (light microscopy $\times 100$ ).

$62.5 \%$ of $S$. aureus and $47.1 \%$ of CNS. The prevalence of icaA gene was low versus that of icaD gene. The bap gene was detected in only 4 isolates, one $S$. aureus isolate $(2.5 \%)$ and 3 CNS isolates $(4.4 \%)$.

\section{Discussion}

Biofilms are related to pathogenicity, and it has been proposed that Staphylococcus biofilms are major causes of recurrent and chronic mastitis in dairy cattle [23]. Numerous authors stated that bacteria in a biofilm are more resistant to antibiotics than in their planktonic form [24, 25].

In this study, slime production was examined qualitatively, depending on colony morphology of 108 bovine mastitis isolates of genus Staphylococci (S. aureus and CNS) produced on Congo red agar. Some differences between researches were apparent with respect to interpretation of CRA test results. In that respect, both bright black colonies [26] and black colonies $[8,27]$ were considered as a positive result. However, Cucarella et al. [5] described the dry crystalline surface (rough colony morphology) as a positive result, disregarding the color (black or pink). Such discrepancy when interpreting the results may possibly be due to the fact that the test itself was not originally designed for investigating $S$. aureus isolates as reported by Freeman et al. [28]. In this investigation, according to Dubravka et al. [14] isolates that formed black/rough colonies were recorded as strong slime producing, whereas isolates forming red/smooth colonies were described as nonslime producers. The smooth black and dry red colonies were considered as indeterminate result. As displayed in Table 2, slime production was detected in 33 $(30.6 \%)$ isolates that produced characteristic black colonies of dry crystalline consistency while 32 isolates (29.6\%) produced smooth red colonies. Also, 27 isolates (25\%) produced black colonies with smooth shiny surfaces were interpreted as indeterminate result. Furthermore, 16 isolates (14.8\%) produced red colonies with dry rough consistency were described as indeterminate result. Totally, 76 isolates $(70.4 \%)$ were found to be slime producers with variable degrees.

MTP method was reported to have high specificity, sensitivity, and positive predictive value [13]. As shown in Table 3, using MTP method, $96.3 \%$ of the isolates were biofilm producers with variable production levels. This high prevalence agreed with that reported by Seo et al. [29] who noted that approximately $80 \%$ of their isolates produced slime with the MTP method but with variable degrees of production. On the contrary, lower prevalence rates of biofilm producers among S. aureus and S. epidermidis bovine mastitis isolates were also reported to be $29.41 \%$ [30] and $37.5 \%$ [8]. Comparison of results obtained by CRA method versus that of MTP method was declared in Table 4. Out of 32 biofilm negative Staphylococcus isolates (13 S. aureus and 19 CNS) by CRA method, 28 isolates were positive by MTP method but with different degrees of production (4 strong, 8 moderate, and 16 weak) while only 4 CNS isolates were negative by both methods. Congo red agar (CRA) method showed little correlation with MTP method where only 76 (70.4\%) of the isolates were positive by both methods with kappa coefficient 0.167 (slight agreement). The sensitivity and specificity of CRA method versus MTP method as gold standard were calculated to be $73.1 \%$ and $100 \%$, respectively. Although CRA method was easy to perform and less time consuming, however, our findings confirm what was reported by Mathur et al. [13] that CRA method cannot be recommended for detection of biofilm formation by Staphylococci alone.

Difference between results of CRA and MTP methods can be attributed to the fact that phenotypic expression of biofilm 


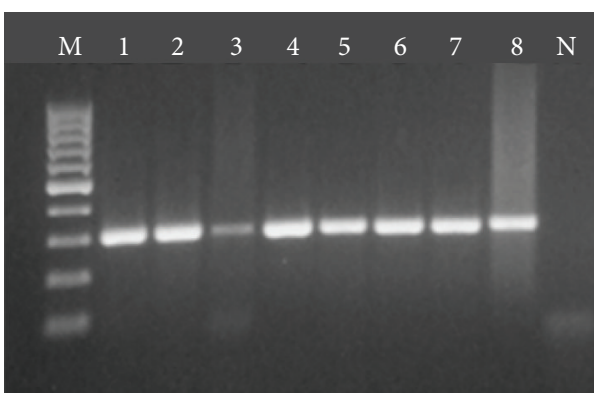

(a)

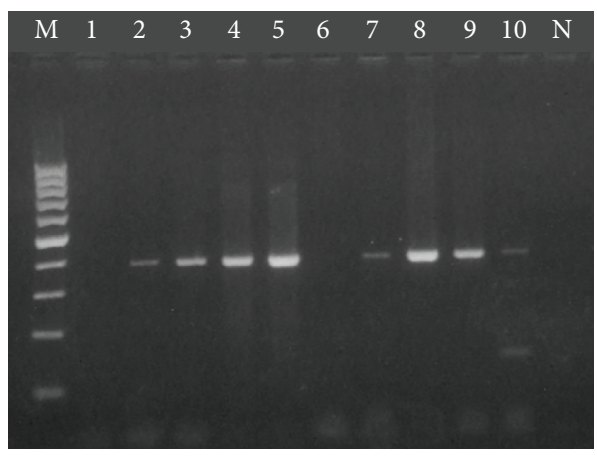

(c)

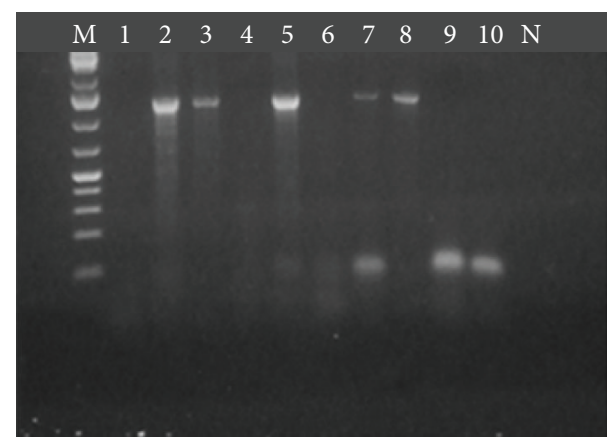

(b)

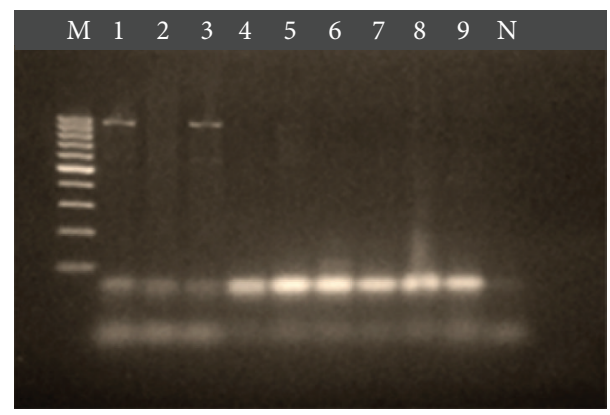

(d)

FIgURE 4: Agarose gel electrophoresis of PCR products stained with ethidium bromide. (a) eno gene (302 bp), M: 100 bp ladder DNA marker, 1-8: positive samples, N: negative control. (b) icaA gene (1315 bp), M: $1 \mathrm{~kb}$ plus DNA marker, 2, 3, 5, 7, 8: positive samples, 1, 4, 6, 9, 10: negative samples, N: negative control. (c) icaD gene (381 bp), M: $100 \mathrm{bp}$ ladder DNA marker, 2-5, 7-10: positive samples, 1, 6: negative samples, N: negative control. (d) bap gene (971 bp), M: 100 bp ladder DNA marker, 1, 3: positive samples, 2, 4-9: negative samples, N: negative control.

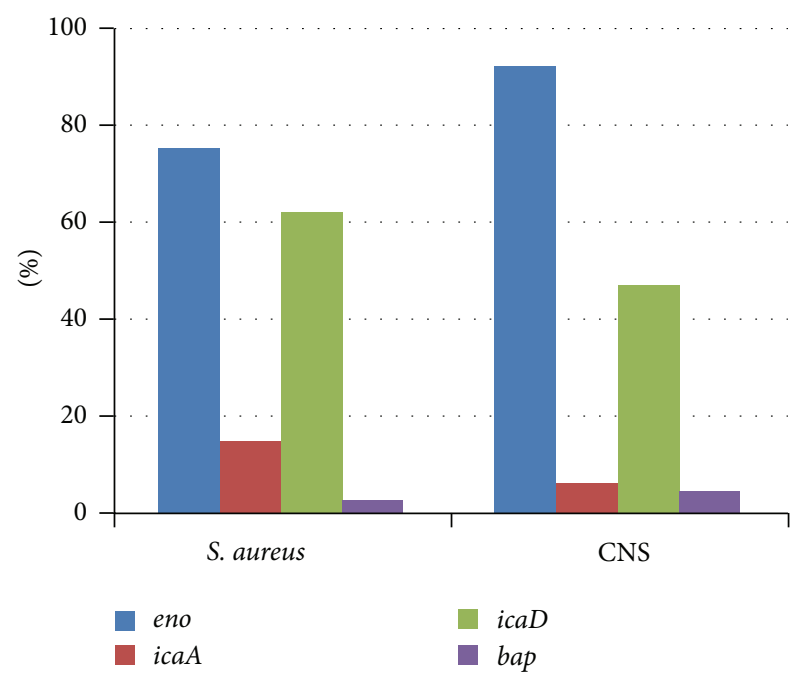

FIGURE 5: Prevalence of biofilm related genes in S. aureus and CNS isolated from bovine mastitis milk.

formation is highly sensitive to in vitro conditions and hence can be detected variably by different methods. Also, both tests measure the same phenomenon but in different ways. CRA has been used as indirect indicator of polysaccharide production $[16,31]$.
Additionally, Indian ink was used to stain wet preparations of Staphylococcus isolates; all the 108 isolates except 4 biofilm negative CNS showed distinct halo transparent zones denoting to EPS layer surrounding the cells (Figure 3). The size of the hallo zones enlarged with the ability of the isolates to produce biofilms. This result proposed the use of Indian ink staining as a rapid screening test for biofilm formation when other methods are not feasible.

As combination of phenotypic and genotypic methods would be recommended for identifying biofilm producing strains, the detection of 4 biofilm related genes and their incidence in Staphylococcus isolates were investigated using simplex PCR reactions (Figures 4 and 5). Because of the absence of a reference positive control for each of the studied genes, the DNA of all isolates was first examined by Staphylococcus genus specific primers to monitor the quality of the DNA for amplification and to exclude any false negative results. All the 108 Staphylococcus isolates successfully amplified the specific $228 \mathrm{bp}$ of the $16 \mathrm{~S} r R N A$ gene of genus Staphylococcus. This amplification confirmed all the isolates to be Staphylococci and ensuring the suitability of the DNA for amplification.

The intercellular adhesion (ica) locus, consisting of the genes ica $A D B C$, has been reported to have a potential role as a virulence factor in the pathogenesis of mastitis in ruminants [4]. Among the ica genes, icaA and icaD have been reported to play a significant role in biofilm formation in S. aureus 
and S. epidermidis [32]. The prevalence rates of icaA and icaD genes were $15 \%$ and $62.5 \%$ in $S$. aureus isolates and $5.9 \%$ and $47.1 \%$ in CNS isolates, respectively (Figure 5). Although the majority of researches reported the icaA and icaD to be nearly similar in incidence $[2,4,30]$, our results agreed with Ciftci et al. [33] who found that 16 and 38 out of 59 strains were positive for icaA and icaD genes, respectively. This difference in the prevalence rates can be attributed to variation in DNA sequences which may lead to failed amplification of the gene in some isolates leading to false negative results [34]. This was previously reported by Simojoki et al. [35] who excluded icaA and icaD results from their work because their primers, although were able to detect the genes in $S$. aureus isolates, were not able to detect the genes in known icaA and icaD positive $S$. epidermidis.

Detection of $i c a A$ and icaD was not well correlated with biofilm production on MTP methods (Table 5). Presence of icaA or icaD negative biofilm positive isolates can be accounted for by an ica gene independent control of slime production/adhesion mechanism [36]. On the contrary, inability of Staphylococcus isolates that were positive for icaA and/or icaD genes to produce biofilm in vitro can be due to point mutation in the locus and/or any other yet unidentified factors that negatively regulate polysaccharide intercellular adhesion synthesis or influence biofilm formation [1]. Also, some experimental evidence supports the development of new clones referred as biofilm negative with both icaA and icaD genes positive [37]. Additionally, lacking of icaA mRNA or icaD mRNA or both was reported to explain absence of phenotypic expression of biofilm [36]. Despite discrepancy between results of ica locus and biofilm phenotypic expression, Vasudevan et al. [4] argued that a better methodology for biofilm detection is to screen strains for ica genes in addition to CRA or MTP methods not to miss the genotypically positive phenotypically negative strains. On the contrary, Ciftci et al. [33] reported that PCR targeting $i c a A$ and $i c a D$ genes may be not sufficient to detect slime production, and further studies targeting other genes should be conducted for accurate evaluation of slime production characters of $S$. aureus strains.

Among the studied genes, eno encoding the lamininbinding protein was the most commonly detected gene in Staphylococcus mastitis isolates under study. The prevalence rates of the eno gene were $75 \%$ and $92.6 \%$ in S. aureus and CNS, respectively (Table 5 and Figure 5). This high prevalence agreed with that of Simojoki et al. [35] who reported the same gene to be the most commonly detected in CNS isolates from mastitis in a percentage of $75 \%$. Also, this gene was detected with the highest rate in airborne Staphylococci (83\%) when compared with animal isolates (56\%) as reported by Seo et al. [29].

The bap gene encoding the biofilm associated protein was the least detected gene where it was only detected in one S. aureus $(2.5 \%)$ isolate and $3(4.4 \%)$ CNS isolates (Table 5 and Figure 5). This very low prevalence was previously reported by Cucarella et al. [5] who detected the bap gene in $5 \%$ of $S$. aureus obtained from bovine subclinical mastitis. This gene is also detected in other Staphylococcus species, including S. epidermidis, S. chromogenes, S. simulans, and S. hyicus [34]. Other authors did not detect the bap gene in their Staphylococcus isolates [29, 35, 38].

Antimicrobial therapy of mastitis is based on results of susceptibility tests in vitro; therefore, new tests must be adopted to select the antibiotic of choice for treatment of biofilm positive strains where ordinary test selects antibiotics that are effective only in inhibiting planktonic bacterial population, whereas bacteria in biofilm resist and survive the treatment and provide materials for further growth [39].

\section{Conclusions}

Findings of the present study demonstrated the great ability of both $S$. aureus and CNS bovine mastitis isolates to form biofilms with different degrees of production using different methods. This must be considered as an alarming situation, and so attention must be paid toward implementation of new ways for effective prophylaxis, control, and treatment of such infections in the dairy farms.

\section{Conflict of Interests}

The authors have no conflict of interests.

\section{Authors' Contribution}

Samah F. Darwish and Hanaa A. E. Asfour contributed equally to the work.

\section{References}

[1] S. E. Cramton, C. Gerke, N. F. Schnell, W. W. Nichols, and F. Götz, "The intercellular adhesion (ica) locus is present in Staphylococcus aureus and is required for biofilm formation," Infection and Immunity, vol. 67, no. 10, pp. 5427-5433, 1999.

[2] D. Vancraeynest, K. Hermans, and F. Haesebrouck, "Genotypic and phenotypic screening of high and low virulence Staphylococcus aureus isolates from rabbits for biofilm formation and MSCRAMMs," Veterinary Microbiology, vol. 103, no. 3-4, pp. 241-247, 2004.

[3] R. N. Zadoks, W. B. van Leeuwen, D. Kreft et al., "Comparison of Staphylococcus aureus isolates from bovine and human skin, milking equipment, and bovine milk by phage typing, pulsedfield gel electrophoresis, and binary typing," Journal of Clinical Microbiology, vol. 40, no. 11, pp. 3894-3902, 2002.

[4] P. Vasudevan, M. K. M. Nair, T. Annamalai, and K. S. Venkitanarayanan, "Phenotypic and genotypic characterization of bovine mastitis isolates of Staphylococcus aureus for biofilm formation," Veterinary Microbiology, vol. 92, no. 1-2, pp. 179-185, 2003.

[5] C. Cucarella, M. Á. Tormo, C. Úbeda et al., "Role of biofilm associated protein Bap in the pathogenesis of bovine Staphylococcus aureus," Infection and Immunity, vol. 72, no. 4, pp. 2177-2185, 2004.

[6] L. K. Fox, R. N. Zadoks, and C. T. Gaskins, "Biofilm production by Staphylococcus aureus associated with intramammary infection," Veterinary Microbiology, vol. 107, no. 3-4, pp. 295299, 2005. 
[7] M. B. Melchior, J. Fink-Gremmels, and W. Gaastra, "Comparative assessment of the antimicrobial susceptibility of Staphylococcus aureus isolates from bovine mastitis in biofilm versus planktonic culture," Journal of Veterinary Medicine B, vol. 53, no. 7, pp. 326-332, 2006.

[8] M. Oliveira, R. Bexiga, S. F. Nunes et al., "Biofilm-forming ability profiling of Staphylococcus aureus and Staphylococcus epidermidis mastitis isolates," Veterinary Microbiology, vol. 118, no. 1-2, pp. 133-140, 2006.

[9] D. McKenney, J. Hübner, E. Muller, Y. Wang, D. A. Goldmann, and G. B. Pier, "The ica locus of Staphylococcus epidermidis encodes production of the capsular polysaccharide/adhesin," Infection and Immunity, vol. 66, no. 10, pp. 4711-4720, 1998.

[10] G. F. M. Gad, M. A. El-Feky, M. S. El-Rehewy, M. A. Hassan, H. Abolella, and R. M. A. El-Baky, "Detection of icaA, icaD genes and biofilm production by Staphylococcus aureus and Staphylococcus epidermidis isolated from urinary tract catheterized patients," Journal of Infection in Developing Countries, vol. 3, no. 5, pp. 342-351, 2009.

[11] R. A. Nasr, H. M. AbuShadady, and S. H. Hussein, "Biofilm formation and presence of icaAD gene in clinical isolates of staphylococci," The Egyptian Journal of Medical Human Genetics, vol. 13, pp. 269-274, 2012.

[12] P. J. Quinn, B. K. Markey, M. E. Carter, W. J. Donnelly, and F. C. Leonard, Veterinary Microbiology and Microbial Disease, A Blackwell Science, 2002.

[13] T. Mathur, S. Singhal, S. Khan, D. J. Upadhyay, T. Fatma, and A. Rattan, "Detection of biofilm formation among the clinical isolates of staphylococci: an evaluation of three different screening methods," Indian Journal of Medical Microbiology, vol. 24, no. 1, pp. 25-29, 2006.

[14] M. Dubravka, S. Lazić, V. Branka, P. Jelena, D. Bugarski, and S. Zorica, "Slime production and biofilm forming ability by staphylococcus aureus bovine mastitis isolates," Acta Veterinaria, vol. 60, no. 2-3, pp. 217-226, 2010.

[15] S. Stepanović, D. Vuković, I. Dakić, B. Savić, and M. ŠvabićVlahović, "A modified microtiter-plate test for quantification of staphylococcal biofilm formation," Journal of Microbiological Methods, vol. 40, pp. 175-179, 2000.

[16] R. Baselga, I. Albizu, M. De la Cruz, E. Del Cacho, M. Barberan, and B. Amorena, "Phase variation of slime production in Staphylococcus aureus: implications in colonization and virulence," Infection and Immunity, vol. 61, no. 11, pp. 48574862, 1993.

[17] R. Bennama, M. Fernández, V. Ladero, M. A. Alvarez, N. Rechidi-Sidhoum, and A. Bensoltane, "Isolation of an exopolysaccharide-producing Streptococcus thermophilus from Algerian raw cow milk," European Food Research and Technology, vol. 234, no. 1, pp. 119-125, 2012.

[18] U. Reischl, M. Pulz, W. Ehret, and H. Wolf, "PCR-based detection of mycobacteria in sputum samples using a simple and reliable DNA extraction protocol," BioTechniques, vol. 17, no. 5, pp. 844-845, 1994.

[19] S. R. Monday and G. A. Bohach, "Use of multiplex PCR to detect classical and newly described pyrogenic toxin genes in staphylococcal isolates," Journal of Clinical Microbiology, vol. 37, no. 10, pp. 3411-3414, 1999.

[20] A. Tristan, L. Ying, M. Bes, J. Etienne, F. Vandenesch, and G. Lina, "Use of multiplex PCR to identify Staphylococcus aureus adhesins involved in human hematogenous infections," Journal of Clinical Microbiology, vol. 41, no. 9, pp. 4465-4467, 2003.
[21] C. Cucarella, C. Solano, J. Valle, B. Amorena, Í. Lasa, and J. R. Penadés, "Bap, a Staphylococcus aureus surface protein involved in biofilm formation," Journal of Bacteriology, vol. 183, no. 9, pp. 2888-2896, 2001.

[22] D. M. Ilstrup, "Statistical methods in microbiology," Clinical Microbiology Reviews, vol. 3, no. 3, pp. 219-226, 1990.

[23] M. B. Melchior, J. Fink-Gremmels, and W. Gaastra, "Extended antimicrobial susceptibility assay for Staphylococcus aureus isolates from bovine mastitis growing in biofilms," Veterinary Microbiology, vol. 125, no. 1-2, pp. 141-149, 2007.

[24] M. B. Melchior, H. Vaarkamp, and J. Fink-Gremmels, "Biofilms: a role in recurrent mastitis infections?" Veterinary Journal, vol. 171, no. 3, pp. 398-407, 2006.

[25] A. Raza, G. Muhammad, S. Sharif, and A. Atta, "Biofilm producing Staphylococcus aureus and bovine mastitis: a review," Molecular Microbiology Research, vol. 3, no. 1, pp. 1-8, 2013.

[26] S. Çitak, Ö. Varlik, and N. Gündoğan, "Slime production and DNase activity of staphylococci isolated from raw milk," Journal of Food Safety, vol. 23, no. 4, pp. 281-288, 2003.

[27] A. Jain and A. Agarwal, "Biofilm production, a marker of pathogenic potential of colonizing and commensal staphylococci," Journal of Microbiological Methods, vol. 76, no. 1, pp. 8892, 2009.

[28] D. J. Freeman, F. R. Falkiner, and C. T. Keane, "New method for detecting slime production by coagulase negative staphylococci," Journal of Clinical Pathology, vol. 42, no. 8, pp. 872-874, 1989.

[29] Y.-S. Seo, D. Y. Lee, N. Rayamahji, M. L. Kang, and H. S. Yoo, "Biofilm-forming associated genotypic and phenotypic characteristics of Staphylococcus spp. isolated from animals and air," Research in Veterinary Science, vol. 85, no. 3, pp. 433-438, 2008.

[30] N. B. Dhanawade, D. R. Kalorey, R. Srinivasan, S. B. Barbuddhe, and N. V. Kurkure, "Detection of intercellular adhesion genes and biofilm production in Staphylococcus aureus isolated from bovine subclinical mastitis," Veterinary Research Communications, vol. 34, no. 1, pp. 81-89, 2010.

[31] N. T. Stevens, C. M. Greene, J. P. O’Gara, and H. Humphreys, "Biofilm characteristics of Staphylococcus epidermidis isolates associated with device-related meningitis," Journal of Medical Microbiology, vol. 58, no. 7, pp. 855-862, 2009.

[32] F. Gotz, "Microreview on Staphylococcus and biofilms," Molecular Microbiology, vol. 43, pp. 1367-1378, 2002.

[33] A. Ciftci, A. Findik, E. E. Onuk, and S. Savasan, "Detection of methicillin resistance and slime factor production of Staphylococcus aureus in bovine mastitis," Brazilian Journal of Microbiology, vol. 40, no. 2, pp. 254-261, 2009.

[34] M. Á. Tormo, E. Knecht, F. Götz, I. Lasa, and J. R. Penadés, "Bapdependent biofilm formation by pathogenic species of Staphylococcus: evidence of horizontal gene transfer?" Microbiology, vol. 151, no. 7, pp. 2465-2475, 2005.

[35] H. Simojoki, P. Hyvönen, C. Plumed Ferrer, S. Taponen, and S. Pyörälä, "Is the biofilm formation and slime producing ability of coagulase-negative staphylococci associated with the persistence and severity of intramammary infection?" Veterinary Microbiology, vol. 158, pp. 344-352, 2012.

[36] M. C. Liberto, G. Matera, A. Quirino et al., "Phenotypic and genotypic evaluation of slime production by conventional and molecular microbiological techniques," Microbiological Research, vol. 164, no. 5, pp. 522-528, 2009. 
[37] C. R. Arciola, L. Baldassarri, and L. Montanaro, "Presence of icaA and icaD genes and slime production in a collection of Staphylococcal strains from catheter-associated infections," Journal of Clinical Microbiology, vol. 39, no. 6, pp. 2151-2156, 2001.

[38] E. Vautor, G. Abadie, A. Pont, and R. Thiery, "Evaluation of the presence of the bap gene in Staphylococcus aureus isolates recovered from human and animals species," Veterinary Microbiology, vol. 127, no. 3-4, pp. 407-411, 2008.

[39] M. Fenton, R. Keary, O. McAuliffe, R. Paul Ross, O. 'Mahony J, and A. Coffey, "Bacteriophage-derived peptidase CHAPK eliminates and prevents Staphylococcal biofilms," International Journal of Microbiology, vol. 2013, Article ID 625341, 8 pages, 2013. 

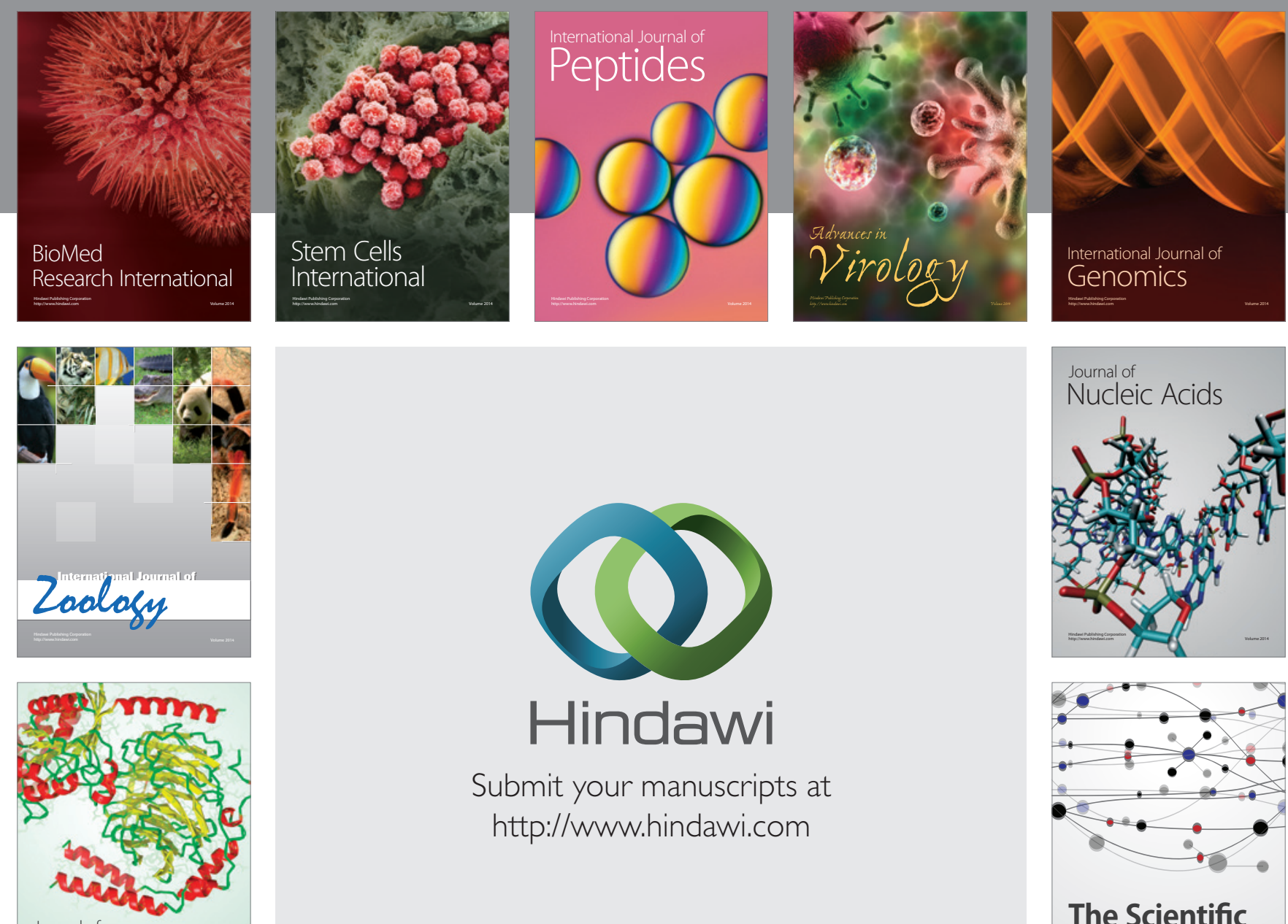

Submit your manuscripts at

http://www.hindawi.com

Journal of
Signal Transduction
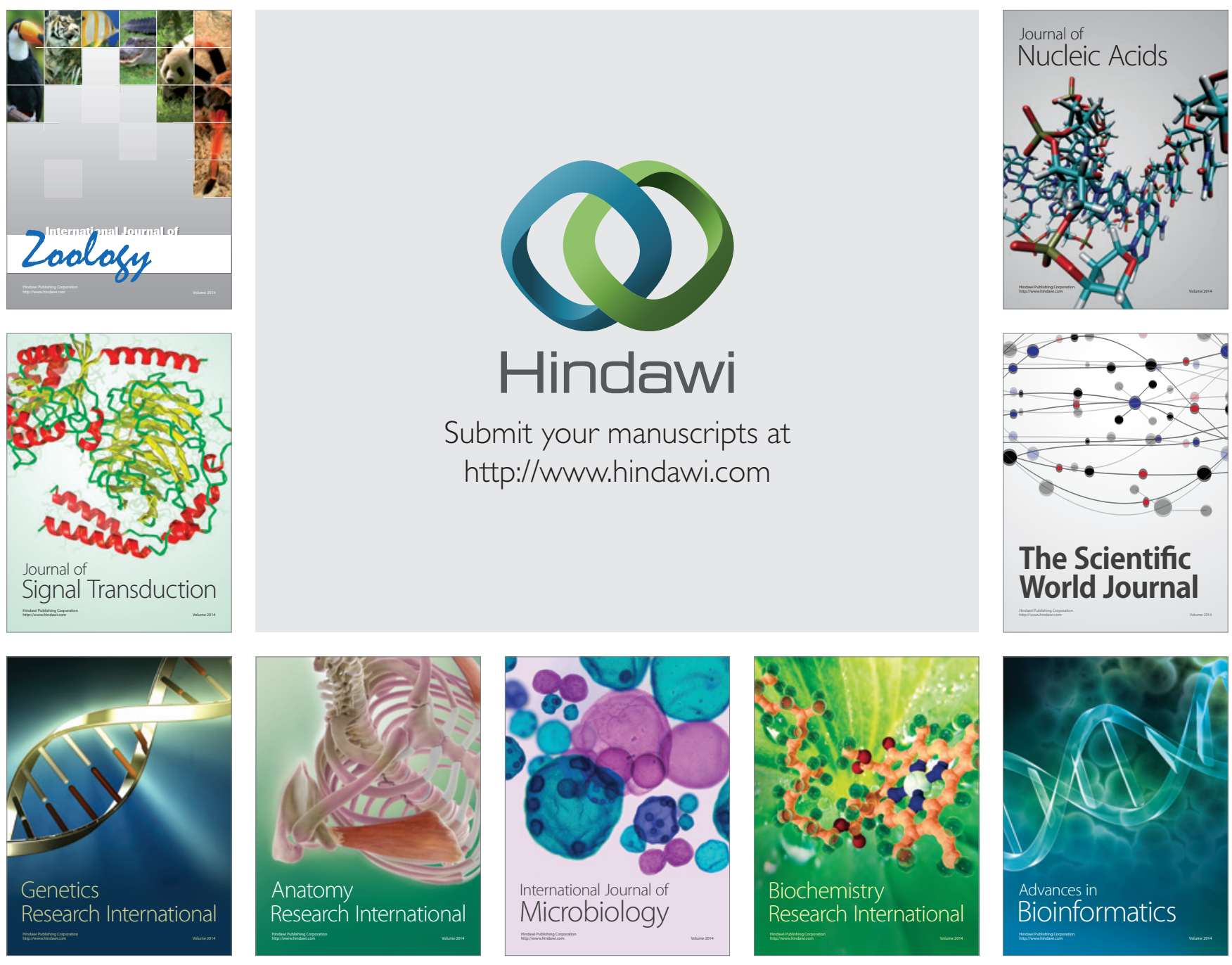

The Scientific World Journal
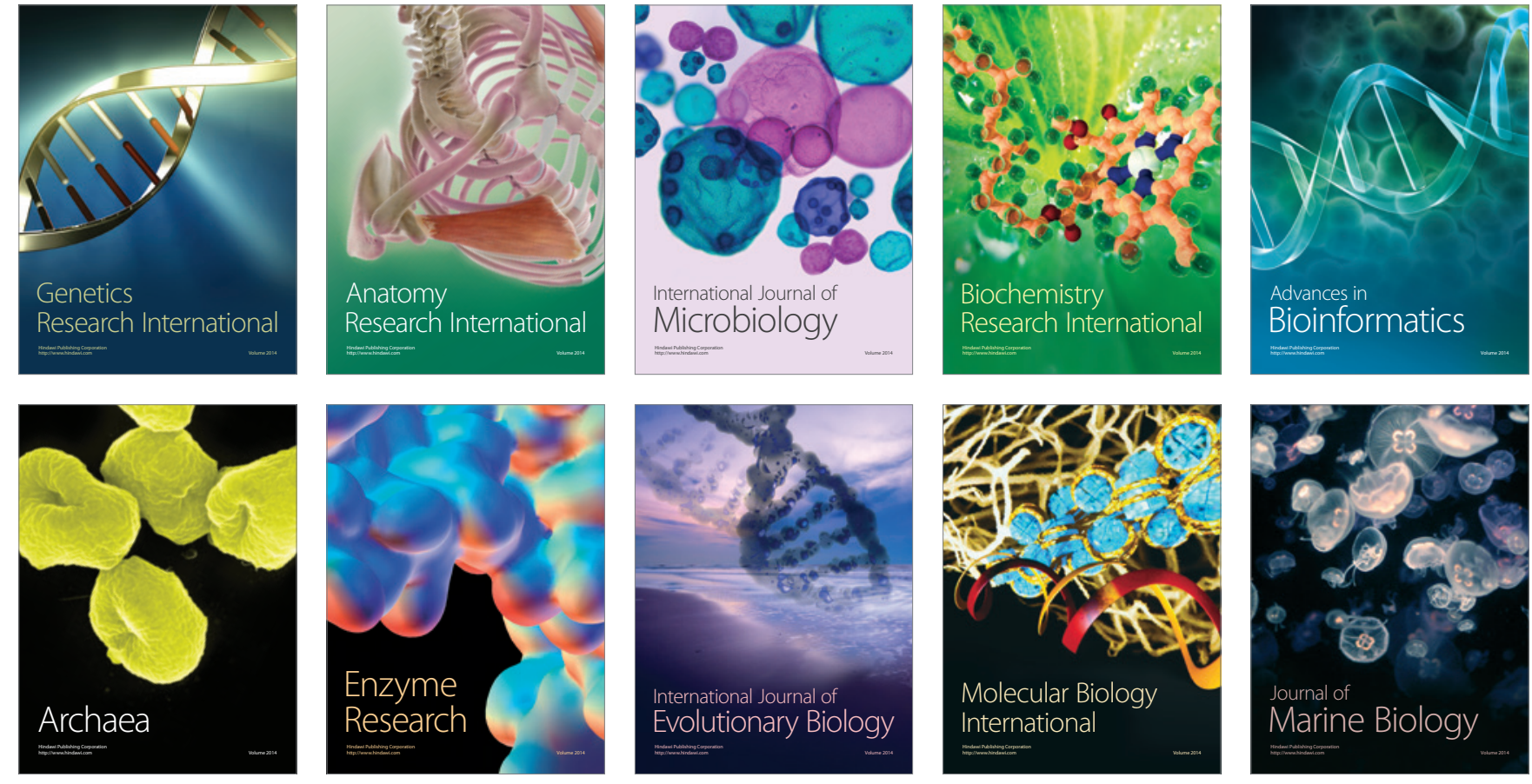